\title{
Toward zero carbon with environmentally friendly transport modes
}

\author{
E. Ö. Aktuğlu Aktan \\ Department of City and Regional Planning, \\ Ylldız Technical University, Turkey
}

\begin{abstract}
The rapid growth of cities, the increase and distribution of population and building intensity, the increase in vehicle ownership, and related to these, Earth's surface turning into built areas, rapidly increases energy consumption (which is not apparent but is vitally important) and also increases the production of carbon.

For the cities of the world to have a sustainable future and be resilient, they must move toward Zero Carbon Emissions, developing strategies and starting implementation as soon as possible.

The aim of this paper is to change the focus of reduction efforts to cities, specifically focusing upon transportation. Carbon, activated carbon, carbon footprints, and the reduction of carbon production in line with the Kyoto Protocol will be examined in terms of transportation issues. International studies on zero carbon emissions will be examined within the context of transportation. The place of environmentally friendly transport modes and their links will be discussed, especially in Chicago city center and in Masdar City, currently being built in Abu Dhabi (construction will be finished by the end of 2020). Recommendations highlight the importance of these discussions on the future of humanity.

Keywords: zero carbon, green goal, carbon footprint, environmentally friendly transport modes, sustainable transportation, Chicago, Masdar.
\end{abstract}

\section{Introduction}

Increasing population, urbanization, industrialization and uncontrolled resource usage cause negative results for living areas. Development transforms nature into an artificial environment. We have to utilize technology, information and other facilities of modern age for our own good. 
Organizations and people from all over the world should cooperate to ensure a sustainable future. A global effort to reduce greenhouse gas emissions can help ensure the world's average temperature does not change. In order to realize this goal, some changes both in the global economy and in the economy of each country will be needed. In this process, each government's plan to achieve a carbonless world will influence the country's future economy and determine the welfare of its citizens.

\section{Why is sustainable transportation important?}

Sustainability can be defined as the ability to become permanent. Sustainability is mainly focused on preventing environmental issues that arise parallel to economical and technological developments and on nature conservation. The concept of sustainable transportation is generally identified with combating air pollution, greenhouse gas emission increase, global warming and climate change however transportation can also have negative effects on very different matters. Transportation systems that are not sustainable create negative economic, social, demographic, cultural and spatial effects in the influence of very different disciplines. The problems caused by non-sustainable transportation begin with air pollution caused by vehicles, greenhouse gases and climate change. Globally, efforts to reduce these impacts by slowing global warming and reducing gas releases have attracted the most attention.

Harmful gases produced by motor vehicles cause air pollution, affecting human health and disturbing Earth's ecological balance.

Transportation system must be designed with human health in mind as much as considerations of things and vehicles. Transportation systems are everchanging parts of cities. Urban areas changed from pedestrian scale cities to sprawled, unperceivable, inaccessible areas primarily due to automobiles.

Vehicular traffic limits interpersonal relations. Each activity that reduces vehicle traffic can affect city life positively. When inner city areas remain pedestrian accessible, transportation is not a problem. When cities lose their pedestrian scale, transportation starts to become a problem [1].

\section{The search for solutions to the case of transportation in urban areas}

The urban policies that are related to transportation in terms of sustainability are:

- The limiting factor of the economic growth being the natural wealth and the necessity of protecting this wealth,

- The necessity of a strategic environmental impact assessment of land-use and zoning planning and establishing a mix of functions(mixed-use) in the direction of reducing the mobility in the process of urban development,

- The necessity of directing the urban lifestyle that would produce less transport by increasing the accessibility,

- Renewable energy sources being the only sustainable option. 
Ecological city models are the cities that have compact city forms and the cities that are sustainable. The purpose of this type of city is to protect natural resources and to design these cities with nature in its best form. For the sustainability of this ecological system, ecological knowledge should be enhanced, so the consumption of natural resources can decrease.

Policies that encourage walking provide potential benefits in terms of health, then environment and economics. The first goal of a walking and public transportation-oriented strategic plan approach is mainly to make people choose walking for short journeys and choose a mixture of walking and public transportation for long journeys. In order to increase pedestrian access in the city, to create a highly qualified urban environment, and to revitalize public areas, the city should be formatted in a planned and targeted approach in time.

\subsection{The ecological footprints of cities}

As city people, we need to know what levels of production and consumption are sustainable; that is, what levels are within the Earth's environmental limits. In order to assess our impacts, the Canadian ecologist William Rees and his colleague Mathis Wackernagel developed the concept of the ecological footprints of nations and cities. They define these as the areas required to supply nations and cities with food and forest products and to absorb their output of wastes, particularly their output of carbon dioxide.

'The ecological footprint of rich cities can be up to 300 to 500 times their surface area, or six to ten hectares per person. The much more frugal cities of developing countries usually have a much smaller per capita footprint.' [2, p. 114].

'Walkability is the cornerstone and key to an urban area's efficient ground transportation. Every trip begins and ends with walking. Walking remains the cheapest form of transport for all people, and the construction of a walkable community provides the most affordable transportation system any community can plan, design, construct and maintain. Walkable communities put urban environments back on a scale for sustainability of resources ... and lead to more social interaction, physical fitness and diminished crime and other social problems. Walkable communities are more liveable communities and lead to whole, happy and healthy lives for the people who live in them.' [2, p. 151].

\section{Case studies}

In many cities, plans are being made to decrease private vehicle usage and bring carbon emissions within the scope of sustainability. One example, the Chicago Central Area DeCarbonization Plan examines all the negative factors in the city's Loop Area, which is an existing city center, and presents solutions. In Masdar 
City, which will be completed in 2020, a holistic approach is aiming to create " 0 " carbon production. The solutions identified by these studies are as follows.

\subsection{The Chicago central area decarbonization plan}

Chicago has long been a world leader in innovations of all kinds, and its response to the need for drastic environmental action to combat climate change is no exception. In 2008, Chicago developed the Chicago Climate Action Plan (CCAP) to begin to address these issues. This is an examination and exploration of the issues that the CCAP deals with and how they may be implemented, focusing on the Chicago Loop area. It also examines the 2030 Challenge, which has an aggressive goal of 80 percent reduction in carbon emissions by 2030 for new and renovated buildings. In this article the mobility part of the plan is discussed. DeCarbonization allows cities to develop as centers of healthy, multifaceted lifestyles with minimal environmental footprints [3].

\subsubsection{Carbon reduction goals [4]}

The DeCarbonization Plan study area is mainly comprised of the central business district of Chicago, and includes its energy-consuming buildings and the workers who commute to them. The strategies of this section are focused on increasing ridership of the existing and proposed upgraded mass transit systems into the Loop.

To make mass transit more appealing, several issues are studied. Cross-town access from the existing suburban transit hubs on the west side of the Loop is difficult. Offices in the River East neighborhood currently have to run shuttles from Metra stations to their buildings to keep their space competitive in the office real estate market.

While modes of transit are key in any discussion of transit-oriented development, the subject of walking is just as important. In a Chicago winter, encouraging walking requires sheltered paths to make the Loop a true transitoriented neighborhood. Many experienced downtown commuter workers use buildings with through-block corridors to spend as much of their foot commute as possible inside the buildings. There are existing, albeit ill-maintained, underground walkways in downtown Chicago to address this problem. There are also several grade-level through-block connections.

Bike paths are discontinuous, making it difficult to get from many parts of the city into the heart of the Loop. There are also significant safety concerns with existing Loop bike routes because they're shared with buses, taxis and cars rather than being dedicated solely for bicycles.

By updating to new, more efficient equipment, technologies and infrastructure for rail, bus and taxis, we can realize significant carbon savings. Improving pedestrian and bicycle amenities will also decrease automobile use. Adding new transit options such as one-way car/scooter/bicycle programs will further reduce the need for private car ownership, reducing carbon emissions. 
Rail

Currently the Loop is well served by CTA El trains and buses. There are also four Metra stations within the study area. However, there are obvious abrupt disconnects between these systems. There are strategies in the current Chicago Central Area Action Plan that are designed to address this over time. The strategies would improve connectivity to the system.

The second main issue is the overall quality of the El ride. This can be improved by the strategies like; rider comfort, rider information, transit stations... Studies have shown that higher-quality rail transit does make a significant difference in ridership because riders feel safe and trains are convenient.

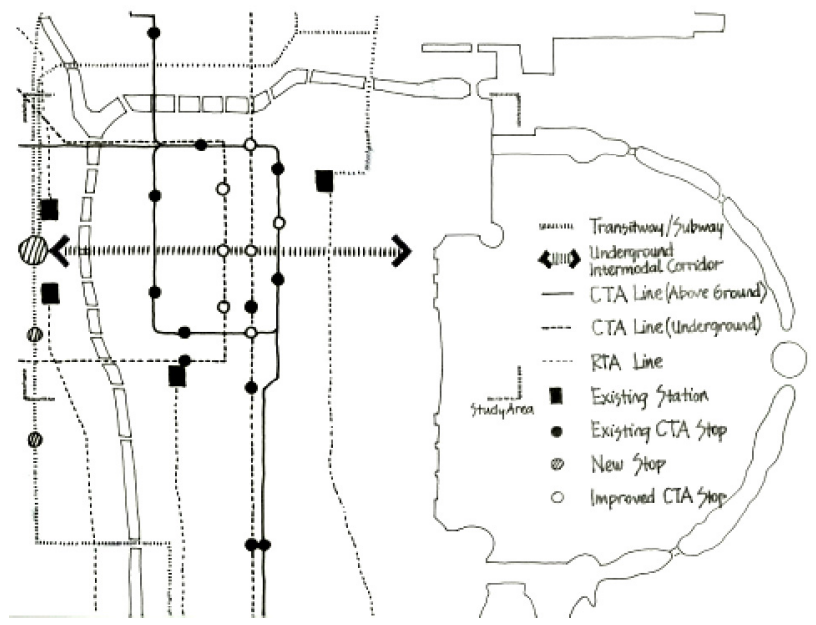

Figure 1: $\quad$ The loop - rail (interpretation of [4, p. 107]).

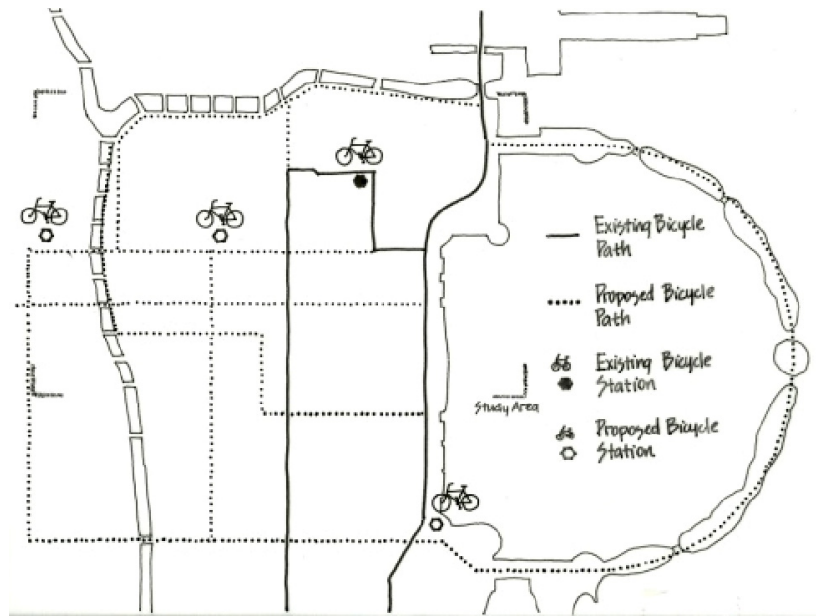

Figure 2: $\quad$ The loop - bicycle paths (interpretation of [4, p. 109]). 


\section{Bicycle paths and bicycle sharing}

Loop bicycle lane safety improvement - There's a strong need for at least one dedicated, safe east-west bicycle route from Canal Street to Millennium Park and a north-south bicycle route connecting north Loop and south Loop neighborhoods to the central Loop.

Bike repair, storage and shower - The theft rate for bicycles in the Loop is very high, even when bicycles are locked. It would also be beneficial to incentivize commercial buildings to provide bicycle storage and showers.

Riverwalk bike path - The Chicago Riverwalk forms an important east-west connection from the lakefront bicycle path to the central Loop. However, its bike path is not continuous and has the potential to be expanded.

Bicycle rentals - Rentals have the potential to be more commuter-friendly through better rates and one-way options.

\section{Car sharing and smart transit}

There is currently no scooter sharing, bike sharing or one-way car sharing available in the Loop.

Parking space identification - With existing security monitoring infrastructure and additional remote sensing technology, the location and price of parking spaces could be transmitted to vehicles to expedite and improve the efficiency of this process.

Real-time congestion charging - A system in which vehicles are recognized and charged for roads use is a unique way to control the flow of traffic through economic motivators. Similar to the smart grid technology used for demand management of electricity, vehicles could be charged based on their emissions and the rush-hour congestion of certain roads.

On-street parking - More pedestrian-friendly streets with limited parking could relieve congestion. Due to the rising cost of street parking through the introduction of pay-boxes, the use of parking garages is a viable alternative for many people who visit or commute by car.

Truck traffic - Extra fees for trucks, limited hours for deliveries or stricter emissions standards could also reduce carbon emissions from trucks, but the economic impacts of such measures would need to be studied.

Taxis

Green taxis - A city requires a mix of energy efficient vehicle types to create an effective, low carbon solution to the taxi system.

Chicago Taxi prototype - Similar to the London cab model, the Chicago Taxi could be designed and built in Chicago, creating jobs and generating revenue that stays in the city. The car would also include a signaling system to let other motorists know when a passenger was exiting the vehicle.

\section{Underground pedway}

The underground pedway system has the potential to be revitalized if new policies are put into place. The first step is better connectivity. If a commuter knows that they will be able to reach their destination underground without coming to a dead end, new confidence in the system can be created. Connections to train stations and subway stations can also be incorporated for added 
convenience. An increase in pedestrian traffic will encourage retail activity below grade.

\section{Intermodal transit}

Integrating public transportation areas with access to train, bus, bike and taxi services, as well as linking to offices and residential areas, can create dynamic urban centers. These transit centers work to integrate above and below grade amenities, both existing and new.

Connections to airports by rail and regional rail systems make these centers hubs for urban activity.

\section{Pedestrian initiatives}

A new, larger facility closer to commuter connection would encourage bicycle commuting.

\section{One-way car and bicycle sharing}

When a commuter wants to go somewhere, he or she can simply walk to the nearest stack, swipe a card to pick up a vehicle, and drive. They then drop off the vehicle at the stack closest to their destination.

\section{Green corridor}

Creating a multi-level East-West intermodal axis along Monroe Street is proposed. This idea is consistent with current master planning for the central Loop. The Monroe corridor has the potential to be a convenient link for transit and pedestrians, and a thriving retail space. Its central location in the Loop will make it a hub for commuters.

The green axis is the main spine that links a series of smaller green plazas that support Loop inhabitants during the day and the evening. The green connections improve transportation, amenities and livability; reduce the heat island effect and storm water treatment requirements; and increase air quality.

\subsection{Masdar City}

Abu Dhabi, the capital of the United Arab Emirates, is located on the Persian Gulf, which due to its shallowness heats up along the shore to around $35^{\circ} \mathrm{C}$ in the summer; daytime sea breezes push warm and humid winds into the city from the northwest. Therefore the city has a very hot-up to $47^{\circ} \mathrm{C}-$ and humid climate in summer. Prior to air conditioning, the location was used only during late fall, winter, and spring for the pearl diving business. During the summer, people moved to Al Ain in the mountains to escape the humidity (but not the heat). Nevertheless, during six months of the year, outdoor conditions are comfortable and allow inhabitants to leave their windows open.

Masdar Development, the vision of the UAE government to build the world's first carbon-neutral city, sited here at one of the sunniest places on the planet, had to take into consideration these conditions as well as the high solar gains. Although outdoor comfort has been ignored in the rest of contemporary Abu Dhabi, with its wide avenues on which pedestrians almost faint before they reach the other side of a street, good urban development is required. 
The master plan, based on several analytical computer evaluations and windtunnel models, proposes narrow streets to protect against the sweltering heat and to keep the street spaces cooler than those outside the city. In limiting street length and influencing street orientation, the "cold island" of Masdar reinterprets traditional local wind towers, ventilating street spaces at night and protecting them against the hot summer winds during the day. "Green fingers" reach through the city from northwest to east to allow for basic ventilation and to catch the cooler east winds. All these efforts ensure that the thermal and visual comfort of the city spaces have a positive direct impact on building loads [5].

In Abu Dhabi, Norman Foster makes a much more serious effort with his zero-carbon city, Masdar, which will have no cars and will be carbon-neutral by using technologies that are still to be revealed.

“... a new 6 million square meter sustainable development... uses traditional planning principals of a walled city, together with existing technologies, to achieve a zero carbon and zero waste community... the city itself is car free... with a maximum distance of $200 \mathrm{~m}$ to the nearest transport link and amenities."

Foster and Partners (in [6]).

Masdar, currently under construction, is an attempt to create the first carbonneutral, zero-waste development. The project was conceived as a car-free development from the outset. This makes Masdar the first effort to develop an urban fabric - accommodating about 70,000 people during the day - without allowing cars to circulate. The solution was to concentrate land use in a dense area of 1.5 square kilometers. Access to the site is granted by private transport Abu Dhabi has virtually no public transport at the moment, although it is planning a different future- from a light-rail transit (LRT) system connecting the development with the more residential area of the $\mathrm{Al}$ Raha development to, in the long term, an underground connection as well as a fleet of buses and other high-occupancy vehicles. The ambitious aim is to achieve 40 percent access to the site by private transport and the remaining 60 percent via public transport.

On reaching the development using private transport, you park at one of the nine car parks located on the perimeter.

If you live in the development, you will be allowed to drive to the "walled" part of the city. If coming by bus or other high-occupancy vehicle, you will be dropped off at the ground floor of the car park. If accessing the city with the LRT system, you will be able to directly enter the heart of the citadel.

The most innovative element of Masdar is the personal rapid transit (PRT) system of fully automated vehicles that will allow access to the city from the car and movement within the city itself. The system represents a breakthrough in the transport world. The 38-kilometer network will accommodate 1.800 vehicles at about 87 stations for passenger; the PRT will also stop at about 120 freight stations, allowing for widespread distribution of goods. The PRT technology is relatively simple, based on electrical engines operated by lithium batteries. The complexity is constituted by the supervisory control system, which the vehicle fleet will have underneath, governing berths, paths, recharging, and so on. 


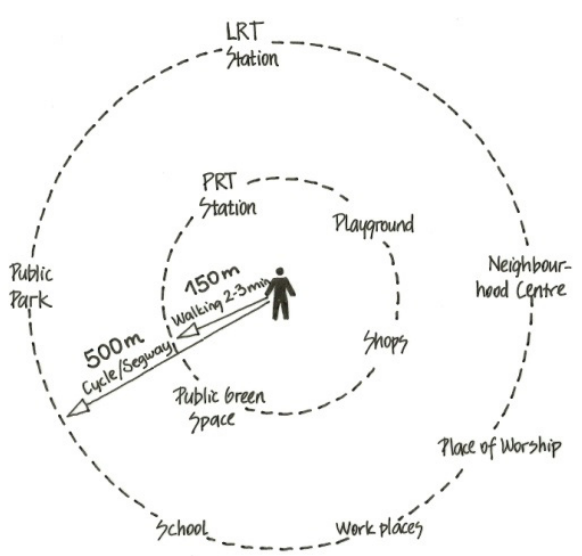

Figure 3: Travel distance to different destinations within Masdar (interpretation of [7, p. 399]).

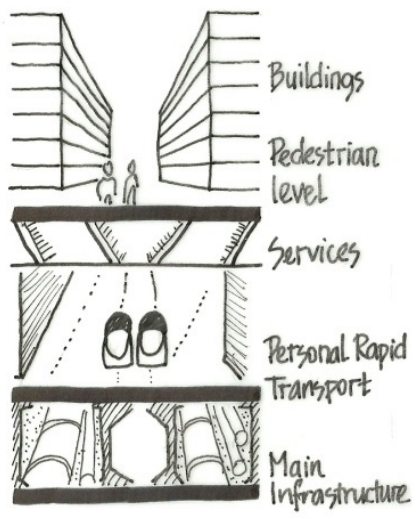

Figure 4

Section through Masdar (interpretation of $[7$, p. 399]).
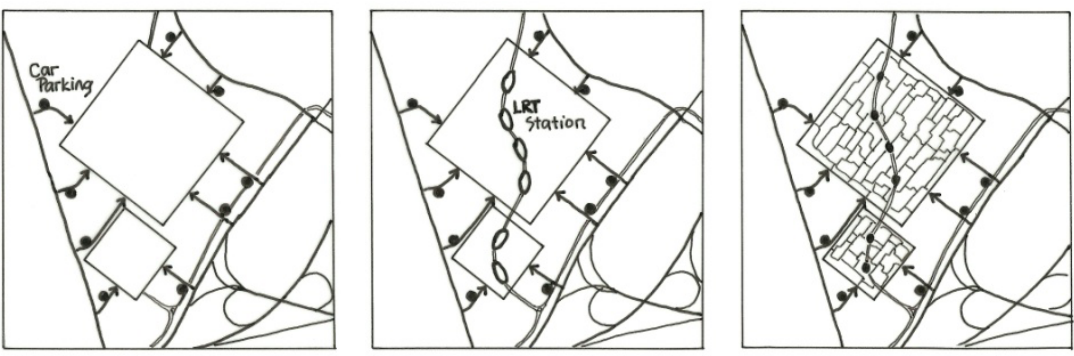

Figure 5: Masdar car park location, LRT stops within Masdar, and PRT routes below the parking deck (interpretation of [7, p. 400]).

The Masdar transport strategy is the first attempt to move away from a traditional transport system to an on-demand system that allows almost door-todoor service - an innovation in the world of transport and maybe a first step to a better future [7].

\section{Conclusion}

The main commonality in both the Chicago Central Area Decarbonization Plan and the plan for the city of Masdar, is the issue is being studied as a whole. To ensure cities and the world exist in the future, it is important to conserve resources. Most importantly, current carbon production should be stopped and ways to decrease its existence should be studied to achieve zero production. 
Cities can become livable places if they are developed according to these principles:

- Access to walking, cycling and public transport should be suitable for the city and at the same time a city form should have compactness that encourages social effects (the need for public space)

- Approach the strategic plan for the city in the context of the city formtransport relationship. Compact, multi-centered, sustainable, mixed use, walking-focused, public transport based policies that complement or direct land uses should be considered.

An established system will be formed when city sub-zones become compact, mixed-use, multi-centered, walkable, and transit rich. This change will require a long time, especially for some portions of the city whose development relied upon automobile transportation. This strategic approach can reach its goal only if it is adopted by all relevant institutions and accepted as vital to the city's future. Changes in line with this strategy will reflect upon the whole city and set a positive example for other areas [1, p. 287].

\section{References}

[1] Aktuğlu Aktan, E. (2011) Criticism of Istanbul inner city urban transportation from the perspective of urban form, Urban Transport XVII, WIT Press, p. 277-289.

[2] Girardet, H. (2004) Cities People Planet, Wiley-Academy, England.

[3] Smith, A., Gordon G. (2011) Toward Zero Carbon - The Chicago Central Area DeCarbonization Plan, Images Publishing, Australia, p. 10.

[4] Smith, A., Gordon G. (2011) Toward Zero Carbon - The Chicago Central Area DeCarbonization Plan, Images Publishing, Australia, p. 103-132.

[5] Thierfelder, A., Schuler, M. (2010/2011) "In Situ: Site Specificity in Sustainable Architecture", (ed. Mohsen Mostafavi with Gareth Doherty) Ecological Urbanism, Lars Müller Publishers, Germany, pp. 590-597.

[6] Koolhaas, R. (2010/2011) “Advancement versus Apocalypse”, (ed. Mohsen Mostafavi with Gareth Doherty) Ecological Urbanism, Lars Müller Publishers, Germany, p. 70.

[7] Parolotto, F. (2010/2011) "Sustainable Mobility in Action", (ed. Mohsen Mostafavi with Gareth Doherty) Ecological Urbanism, Lars Müller Publishers, Germany, pp. 398-401. 